\title{
El matrimonio gitano no permite el acceso a la pensión de viudedad según el TC. ¿Existe discriminación?
}

\section{Eduardo Rojo Torrecilla}

Catedrático de Derecho del Trabajo y de la Seguridad Social. Universidad Autónoma de Barcelona

\section{Introducción}

La sentencia núm. 1/2021 de 25 de enero, dictada por la Sala segunda del TC, que cuenta con un voto particular discrepante muy argumentado a mi parecer, desestima el recurso de amparo interpuesto contra la sentencia dictada por el Pleno de la Sala Social del TS el 25 de enero de $2018^{[1]}$ (Rec. 2401/2016), que también contó con el voto particular discrepante de dos magistradas.

El litigio versa sobre la denegación de la pensión de viudedad a la ahora recurrente en amparo por el INSS, al no haberse cumplido -a su parecer- uno de los requisitos requeridos por la LGSS para poder tener derecho a dicha pensión.

El litigio, desde la perspectiva doctrinal, es especialmente interesante ya que está en juego la existencia, por una parte, de una posible discriminación racial (contra la población gitana) ${ }^{[2]}$ y también de una posible discriminación indirecta por afectar especialmente a dicha población ${ }^{[3]}$. $Y$ además, para poner de manifiesto que tanto en esta sentencia como en la del TS, y en una anterior del TEDH de 8 de diciembre de 2009, asunto Muñoz Díaz c. España, que estimó el recurso interpuesto contra la STC $69 / 2007$ de 16 de abril, en el que se debatía sobre un asunto semejante al ahora resuelto, se ha perdido a mi parecer la oportunidad de analizar el litigio desde la perspectiva de una posible discriminación múltiple o interseccional por razón conjunta de raza y género. La sentencia fue calificada muy gráficamente por el profesor Fernando Rey como "magnífico ejemplo de enfoque race blind, indiferente al factor étnico".

La discriminación múltiple o interseccional ha sido definida por la magistrada Alicia Catalá, en un artículo en el que analiza críticamente la sentencia del TEDH ${ }^{[4]}$, como a que se produce "en todos aquellos supuestos en los cuales varios factores de discriminación actúan simultáneamente produciendo, de forma específica, un determinado tipo de exclusión (como la que sufrió ...... una mujer gitana, perteneciente a un determinado grupo étnico en combinación con su condición de mujer). La simultaneidad en la actuación de los factores que alimentan la discriminación "no es el único requisito que se exige para interpretar con acierto, el fenómeno que estudiamos", enfatiza la magistrada, "sino que también es necesario que, a causa de esa actuación conjunta, se produzca una consecuencia concreta y específica que, aunque derivada de la conjunción de los dos factores, sea propia e 
incluso diversa de la que pudo haberse producido de tenerlos en cuenta por separado", y de ahí que concluya manifestando que "el adjetivo "múltiple", quizás no sea el más adecuado para representar la cuestión a la que nos aproximamos, al menos, si se interpreta como equivalente a suma o combinación por adición, de distintos factores de discriminación y sea preferible el de discriminación "interseccional", para describir un resultado final, particular y propio, consecuencia de la previa y sincrónica actuación de determinados factores discriminatorios concurrentes".

La importancia del asunto abordado se acrecienta -a mi entender- desde el plano político, con su indudable posible repercusión en el jurídico, al haberse aprobado recientemente dos proposiciones no de ley en la sesión del 14 de diciembre de 2020 de la Comisión de Derechos Sociales y Políticas Integrales de la Discapacidad del Congreso de los Diputados, relativas a la población gitana ${ }^{[5]}$.

La primera, presentada por el grupo parlamentario socialista, llama a "impulsar medidas de apoyo al pueblo gitano ante las consecuencias de la crisis provocada por la COVID-19", e incluye la petición al Gobierno, "en coordinación con las Comunidades Autónomas y en el ámbito de sus competencias," de "hacer especial énfasis en la protección de las mujeres gitanas, la infancia y las personas mayores que, dentro de las familias y grupos sociales especialmente vulnerables, son sin duda alguna los más afectados".

La segunda, presentada por el grupo parlamentario interconfederal de Unidas Podemos -En Comú Podem-Galicia en Común, versa sobre "la inclusión del pueblo gitano y la lucha contra el antigitanismo", pidiéndose al gobierno que "vigile los fenómenos de discriminación"; que en los programas de inclusión social se introduzcan de manera integral "ámbitos clave como el empleo..."; y que se desarrollen "acciones de sensibilización para eliminar la discriminación en el acceso, permanencia y promoción al mercado laboral de la población gitana”.

\section{Identificación de la resolución judicial comentada}

Tipo de resolución judicial: sentencia.

Órgano judicial: Tribunal Constitucional (Sala Segunda).

Número de resolución judicial y fecha: sentencia núm. 1/2021, de 25 de enero.

Tipo y número recurso o procedimiento: recurso de amparo núm. 1343/2018.

ECLI:ES:TC:2021:1.

Fuente: BOE.

Ponente: Excma. Sra. Dña. Encarnación Roca Trías.

Votos Particulares: cuenta con un voto particular que formula el magistrado Excmo. Sr. D. Juan Antonio Xiol Ríos.

\section{Problema suscitado. Hechos y antecedentes}

El litigio encuentra su origen en sede judicial con la presentación de una demanda ante los Juzgados de lo Social de Jaén, tras la desestimación por el INSS de la pensión de viudedad solicitada por la que después sería demandante y posteriormente recurrente, por no cumplir el art. 174.3 de la LGSS, es decir "no haberse constituido como pareja de hecho con el fallecido al menos dos años antes del fallecimiento". Consta en los hechos probados de la sentencia de instancia, dictada por el JS núm. 4, el 13 de octubre de 2015, desestimatoria de la demanda, que la actora y su pareja había formalizado una unión matrimonial "conforme a los usos y costumbres gitanos" el 18 de mayo de 1974, habiendo fallecido el marido el 27 de abril de 2014, y que durante todo el periodo de unión no se formalizó inscripción como pareja de hecho. No 
consta en ningún documento oficial la condición de matrimonio de la pareja, apareciendo en el libro de familia como "solteros".

Interpuesto recurso de suplicación, el TSJ de Andalucía (sede Granada) dictó sentencia estimatoria de la pretensión el 20 de abril de 2016 ( $\operatorname{Rec} 2843 / 2015)$, que se basa en buena medida en la doctrina sentada en la sentencia del TEDH de 8 de diciembre de 2009 (asunto Muñoz Díaz c. España). Para el TSJ, "la pareja ha convivido en el municipio en el mismo domicilio y hasta el momento de la muerte y siendo considerados como matrimonio gitano al menos durante 15 años, el rito como tal ceremonia se celebró efectivamente en 1974 conforme a sus costumbres étnicas, en una realidad social y cultural muy distinta a la de hoy, la actora en ese momento no tenía siquiera 15 años, pues nació según el libro de familia en 1959, han tenido 5 hijos en común y no puede entenderse que de mala fe se fingieran como matrimonio gitano en su entorno familiar y social durante tanto tiempo para en su momento futuro cobrar una eventual pensión, por lo que de denegar la pensión se podría producir una discriminación por razones étnicas y culturales".

Contra la sentencia de instancia se interpuso RCUD por el INSS y la TGSS, aportando como sentencia de contraste la del TSJ de Galicia dictada el 27 de marzo de 2013 (Rec. 4657/2010). El TS estimará el RCUD, contra el criterio defendido en el preceptivo informe del Ministerio Fiscal que abogaba por su improcedencia.

En apretada síntesis, cabe decir que el TS procede en primer lugar a repasar su doctrina sobre el requisito de la inscripción como pareja de hecho para tener derecho a la pensión de viudedad, resaltando su importancia y su aceptación por el TC en los casos en los que ha debido conocer de recurso de amparo sobre la misma cuestión, enfatizando que el TC, en algunas de sus sentencias, "ha llegado a reproducir literalmente algunas de nuestras afirmaciones (sobre) la inscripción registral 0 documentación notarial de las parejas de hecho...", recordando su doctrina sobre la diferenciación entre el requisito material de convivencia estable durante un mínimo de cinco años y el formal "ad solemnitatem" de verificación, mediante inscripción registral, de haberse constituido jurídicamente tal pareja con dos años de antelación al hecho causante, siendo así que el Libro de familia es un documento que certifica el matrimonio y la filiación, pero "que no acredita la existencia de pareja de hecho.... Además, resalta que el carácter constitutivo de la inscripción en el Registro de las parejas de hecho, al objeto de poder acceder a determinadas prestaciones, entre ellas la de viudedad, no sólo se prevé en la normativa estatal aplicable (art. 174.3 LGSS), sino que también se recoge en varias de las normas autonómicas reguladoras de las parejas estables pero que no han formalizado vínculo matrimonial.

La Sala repasa igualmente el contenido más relevante de la sentencia del TEDH y pone de manifiesto, para justificar su no aplicación, en contra del criterio defendido por el Ministerio Fiscal, que nos encontramos ante un supuesto diferente del que resolvió el tribunal europeo, poniendo el acento en dos aspectos que a su juicio diferencian claramente ambos casos: "a) que la estimación de la demanda no vino determinada por atribuir eficacia jurídica alguna al «matrimonio gitano», sino porque la validez que le atribuye la comunidad romaní y el reconocimiento de la unión como «matrimonio» en determinados documentos oficiales habían generado en la contrayente comprensible buena fe que justificaba el trato favorable dado por el ordenamiento jurídico a supuestos similares; b) que el Tribunal Europeo no cuestiona la afirmación contenida en la STC 69/2007 [16/ Abril ] -última instancia de su enjuiciamiento en España- de que el principio de igualdad que proclama el art. 14 CE no alcanza a la llamada "discriminación por indiferenciación», al no consagrar un derecho subjetivo al trato normativo desigual ( $\mathrm{FJ} 4^{\circ}$ ); y c) que la pertenencia a una «minoría étnica» no repercutía en la aplicación o en la interpretación de la normativa de que tratamos, sino tan sólo en la configuración de la buena fe"

En los documentos que aparecen recogidos en el caso ahora enjuiciado, no aparece en ninguno de ellos la condición jurídica de matrimonio o pareja de hecho, mientras que en el caso del que conoció el TEDH sí encontramos alguna referencia a la primera, lo que hubiera generado la convicción, de buena fe, de la demandante de 
encontrarse en una situación jurídica protegida por el derecho y que le permitiría acceder a la pensión de viudedad en el supuesto, como así ocurrió, de fallecimiento del causante.

Sin embargo, las circunstancias actuales son diferentes, siendo así que a juicio de la Sala aquello que realmente quiere la parte recurrente es que se equipare el valor del matrimonio según el rito gitano con el de la inscripción constitutiva de la pareja de hecho en el correspondiente Registro, no aceptándose esta tesis porque no está prevista en modo alguno por la ley.

En una línea que pudiera tener puntos de semejanza con el voto particular discrepante de la sentencia del TS (C-A) de 24 de enero (Rec. 98/2017), solo que ahora desde la perspectiva de la mayoría de miembros de la Sala y que por ello quedará recogida en la sentencia, se afirma en primer lugar que aceptar la solución propuesta significaría tratar de peor condición a las parejas auténticas de hecho, es decir las no registradas, aquellas que "por razones ideológicas -tan respetables como las culturales- no se han constituido como pareja de hecho en la forma legalmente prescrita, y a los que -no infrecuentemente- les hemos negado la prestación de viudedad"; y en segundo término, desde un planteamiento restrictivo de aplicación de las reglas y ritos gitanos, que si bien se considera que son merecedores de protección, esta no llega hasta "excepcionar la aplicación de la ley en los múltiples aspectos en que pudiera reflejarse su diversidad étnico-cultural [matrimonio; familia; comportamiento social...], so pena de comprometer gravemente la seguridad jurídica y la uniformidad en la aplicación de aquélla -la ley-“.

La tesis discrepante será defendida por la magistrada Lourdes Arastey, adhiriéndose la magistrada María Luisa Segoviano, considerándose también debidamente acreditada la existencia de contradicción entre la sentencia recurrida y la de contraste, y enfatizando que el asunto del que conoce la Sala es la primera ocasión en la que el TS ha de resolver sobre el alcance que puede desplegar la sentencia del TEDH, "no ya en la posibilidad de equipar el rito gitano al matrimonio, sino en la consideración de las parejas unidas por "matrimonio" gitano en relación con el acceso a la prestación de viudedad".

La tesis del voto subraya el carácter redundante de la inscripción de hecho de la pareja gitana, ya que la ley que ellos consideran aplicable, "su ley gitana" ya la ha convertido desde el momento de la unión "en una unidad matrimonial no cuestionada como tal, y si cabe con más fuerza", y de ahí que los datos disponibles ya avalarían la existencia de esa "unión de hecho" y no requerirían del requisito constitutivo de inscripción en el correspondiente registro, so pena de caer en un formalismo enervante que en nada ayudaría a la protección de los derechos de las personas de etnia gitana y que se han unido como pareja de acuerdo a las reglas y ritos gitanos. De ahí que hubiera podido abordarse la cuestión desde esta perspectiva, y de manera subsidiaria elevar cuestión prejudicial al TJUE. En modo alguno propone el voto particular que la normativa general no sea aplicable a las personas de etnia gitana, sino solo que es posible flexibilizar su interpretación cuando, como ocurre en el caso enjuiciado, "se den las circunstancias que permitan afirmar que el mantenimiento de la convivencia ha sido real, efectivo y con indiscutible carácter de pareja unida maritalmente".

\section{Posiciones de las partes}

Contra la sentencia del TS se interpuso recurso de amparo, con alegación de haberse producido la vulneración del "derecho a no sufrir discriminación racial/étnica (art. 14 CE)"; petición de nulidad de aquella, y reconocimiento del derecho a percibir la pensión de viudedad, con reiteración de la argumentación mantenida en instancia, suplicación y casación, es decir, haber actuado tanto la recurrente como su pareja "con buena fe y con la creencia de la plena validez del matrimonio contraído", habiendo quedado acreditada una convivencia more uxorio con el fallecido por un periodo superior a diez años, por lo que la no aceptación de esta para poder demostrar la existencia de una pareja de hecho, aún cuando no estuviera documentada en los términos regulados por la LGSS, implicaría una discriminación indirecta por cuanto la 
neutralidad de la regla legal "puede afectar particularmente al colectivo gitano, debido a las características particulares de sus tradiciones". El recurso de amparo se apoya en el voto particular emitido en la sentencia del TS y resalta que la inscripción en un registro de parejas de hecho resultaría redundante en este caso, "en la medida en que para la pareja gitana la aceptación de la llamada ley gitana les convierte, a su entender, y al del resto de la comunidad en la que desarrollan su vida, en una unidad matrimonial no cuestionada".

En trámite de alegaciones la representación letrada de la Administración de la SS, en representación del INSS, solicitó la desestimación del recurso, haciendo suya las tesis de la sentencia recurrida. De su argumentación deseo resaltar dos puntos: que la regulación contenida en la LGSS respecto a los requisitos a cumplir por la persona conviviente de una pareja de hecho para poder acceder a la pensión de viudedad "resulta neutral desde la perspectiva racial", y que según la doctrina del TC, el art. 14 "no integra la prohibición de discriminación por indiferenciación, al no consagrar un derecho a la igualdad de trato".

En la misma línea, el Ministerio Fiscal solicitó en su escrito de alegaciones la desestimación del recurso, añadiendo que el hecho de que las uniones gitanas no produzcan efectos civiles en los términos deseados por la recurrente no implica en modo alguno una vulneración del art. 14 del CEDH ("el goce de los derechos y libertades reconocidos en el presente Convenio ha de ser asegurado sin distinción alguna, especialmente por razones de sexo, raza, color, lengua, religión, opiniones políticas u otras, origen nacional o social, pertenencia a una minoría nacional, fortuna, nacimiento o cualquier otra situación"), en relación con el art. 12 ("A partir de la edad núbil, el hombre y la mujer tienen derecho a casarse y a fundar una familia según las leyes nacionales que rijan el ejercicio de este derecho").

En su exposición, el MF, que considera plenamente válida la doctrina sentada por el TS, parte de la premisa de que la legislación española (art. 49 a 52 del CC) no reconoce al matrimonio gitano validez como tal, y que "no existe tampoco un concordato o convenio con los representantes del pueblo gitano equivalente a los celebrados con los representantes de las confesiones religiosas a cuyas ceremonias matrimoniales se les otorga la cualidad de forma valida de prestar el consentimiento en nuestro ordenamiento jurídico". No existiría, pues, la discriminación étnica/racial alegada, ni tampoco una indirecta por el impacto desfavorable sobre el colectivo gitano de una norma en principio neutral, la del registro de la pareja de hecho como elemento constitutivo, ya que este se exige a todas las uniones maritales que quieren constituirse como pareja de hecho, añadiendo que "(la) dificultad de cumplimiento en caso de pertenencia a la etnia gitana se podría considerar equivalente a la de la inscripción del nacimiento de los hijos comunes en el registro civil, cosa esta última que, sin embargo, sí hicieron los padres". Al igual que el TS, es del parecer que existe una diferencia relevante con el caso resuelto en 2009 por el TEDH, por cuanto en el presente no se ha generado por el Estado en la recurrente "una expectativa razonable" de tener derecho a la pensión de viudedad.

\section{Normativa aplicable y doctrina básica}

Al entrar en la fundamentación jurídica, el TC delimita en primer lugar cuál es el objeto del recurso, con repaso a su contenido y de las alegaciones de la parte recurrida y del MF. Pasa después a efectuar una amplia síntesis de la doctrina del TEDH en la sentencia de 8 de diciembre de 2009, asunto Muñoz Díaz c. España, con la finalidad de comprobar, dadas las tesis contrarias mantenidas por la parte recurrente y recurrida (y en sintonía con esta última, y con el TS, el Ministerio Fiscal) "a fin y efecto de comprobar si se trata de casos iguales o, por el contrario, el asunto... difiere del presente caso".

En su síntesis de dicha sentencia el TC ya apunta la línea por donde irá posteriormente su argumentación desestimatoria del recurso, destacando que "...la buena fe de la demandante constituyó, por tanto, el fundamento, la ratio decidendi del pronunciamiento. Tanto es así que, por el contrario, el TEDH rechaza la queja relativa 
a la vulneración del art. $14 \mathrm{CEDH}$ en relación con el art.12 CEDH, y entiende que el hecho de que las uniones gitanas no produzcan efectos civiles en el sentido deseado por la demandante no constituye una discriminación prohibida". Tras recordar los datos fácticos del litigio ahora en juego, tal como quedó recogido en instancia, el TC descarta la existencia de identidad entre ambos casos y por ello concluye que "no resulta aplicable al presente caso la doctrina de la STC 199/2004 de 15 de noviembre, como tampoco, ya se ha visto, la STEDH pronunciada en el caso Muñoz Díaz c. España".

Volverá sobre esta sentencia en el último fundamento de derecho, séptimo, para reiterar la tesis ya expuesta y enfatizar que, a diferencia del caso que resolvió el tribunal europeo basado en la presunción de buena fe de la recurrente, ésta no se dio en el litigio ahora examinado ya que la recurrente en amparo "era plenamente conocedora de la falta de validez de su matrimonio, al haberse celebrado por un rito no reconocido por nuestro ordenamiento jurídico y tampoco formalizó en momento alguno su relación more uxorio en el modo exigido por la legislación para el reconocimiento de su derecho a la prestación de viudedad por el sistema nacional de seguridad social".

No existe para el TC discriminación directa hacia la población gitana porque no se reconozca la unión celebrada conforme a sus usos y costumbres como "una de las formas válidas para contraer matrimonio con efectos de validez civil", al no haber sido reconocida como tal por el legislador en la regulación legal sobre el matrimonio. Por tanto, el TC mantiene su doctrina en lo que respecta a la vinculación del derecho a percibir la pensión de viudedad con la existencia de un vínculo matrimonial en los términos regulados en la normativa vigente.

La Sala confirma la tesis de la sentencia del TS respecto de la inexistencia de discriminación directa por el distinto trato recibido por la unión convivencial no formalizada respecto a la que sí ha cumplido con los requisitos legales, no existiendo en la CE acuerdo a la interpretación efectuada por el TC del art. 14, el amparo de la "discriminación por indiferenciación", por cuanto en el texto constitucional no se consagra un derecho a la desigualdad de trato "por no existir ningún derecho subjetivo al trato formativo desigual".

Tampoco considera el TC que exista discriminación indirecta. Es el contenido más polémico de la sentencia, a mi parecer, ya que se basa en un planteamiento formalista por una parte, apegado a la letra de la norma, y por otra a una manifestación propia con respecto al impacto de la norma sobre la etnia gitana que es justamente aquello sobre lo que se manifiesta diferente criterio jurídico por los votos particulares y basados en la realidad social en la que se opera.

Aquello que niega el TC es, justamente, lo que se debate, y afirmar que la norma neutra y la interpretación neutra no tienen impacto sobre el colectivo gitano queda bastante en entredicho en la cuidada argumentación del voto particular discrepante con aportación de normativa internacional y comunitaria sobre la protección de la comunidad romaní, y con los datos estadísticos sobre la afectación a la población femenina gitana, por lo que sorprende que, sin aportarlos, se remita el TC a anteriores sentencias y afirme que no se evidencian datos estadísticos que avalen la tesis de la discriminación indirecta y que por otra parte, no hay un perjuicio distinto para esta "minoría" que para cualquier otro "colectivo" que opte "por la no formalización de sus relaciones de convivencia o por una formalización que carezca de validez civil". Obsérvese -no creo que requiera ahora mayor argumentación- que no parece posible equiparar a una "minoría" suficientemente reconocida, incluso, como "comunidad nacional" por normas internacionales como sujeto de especial protección con otros "colectivos" indiferenciados y que no poseen la nota propia de especificidad y diferenciación jurídica que puede permitir a quien sí la tiene, o bien, una diferencia de trato legal, o bien, una interpretación de la normativa que evite que bajo la apariencia de neutralidad se produzca una discriminación indirecta hacia dicho colectivo, y en este caso concreto más hacia las mujeres de etnia gitana. 
No niega, obviamente, el TC, que el legislador pueda dictar una regulación que tome en consideración que las uniones celebradas conforme a los ritos y usos gitanos pudieran contar con plenos efectos civiles, y ello "en atención a las singularidades que plantea la etnia gitana", pero no habiéndolo hecho hasta ahora. Tampoco, del marco normativo ni de la interpretación efectuada. Reitera, a modo de síntesis, que "no se advierte....... ni desde el prisma de la discriminación directa ni desde el propio de la indirecta, un trato discriminatorio por razones étnicas o raciales".

El voto particular discrepante del magistrado Juan Antonio Xiol se sustentará en la existencia, a su parecer, de una discriminación de la recurrente por razón de su pertenencia a una "minoría nacional", que llevará a una discriminación indirecta, con perjuicio para quien no puede acceder a la pensión de viudedad por haberse dado la misma "en el trato normativo, administrativo y judicial dispensado a las uniones de vida celebradas conforme a las tradiciones culturales del pueblo romaní a los efectos de lucrar la prestación por viudedad". También manifestará su discrepancia con "el restringido alcance" que la resolución otorga a la sentencia del TEDH.

El voto particular parte de la posibilidad de inclusión de la prohibición de discriminación por pertenencia a una minoría nacional o al origen étnico en la cláusula abierta del art. 14 CE cuando, tras listar algunas causas de discriminación finaliza con la mención a "cualquier otra circunstancia personal o social", no sin dejar de recordar que esa discriminación está expresamente prohibida en la normativa internacional y europea. Para quien lo suscribe, no parece haber dudas, a la vista de la normativa internacional y europea, de estar ante una minoría nacional, la comunidad romaní, que necesita y requiere de especial protección tomando como punto de referencia el Convenio marco para la protección de las minorías nacionales del Consejo de Europa y la propia jurisprudencia del TEDH.

Respecto a la prohibición de discriminación indirecta por pertenencia a una minoría nacional o por razones de origen étnico, el voto subraya que está expresamente regulada en el art. 2 de la Directiva 2000/43/CE y que por ello "no existe obstáculo alguno a la aplicación del parámetro de control desarrollado de manera amplia en la jurisprudencia constitucional de nuestro país -también en la del TEDH y del TJUE- en relación con la discriminación por motivos de género. En la misma línea que el voto particular discrepante de las dos magistradas del TS defenderá, en la tercera parte de su escrito, la existencia de una discriminación indirecta por pertenencia a una minoría nacional "por el diferente tratamiento dispensado para lucrar la prestación de viudedad, por una parte a las uniones de vida celebradas conforme a las tradiciones culturales del pueblo romaní y, por otra, a las uniones de vida no matrimoniales que hayan resultado inscritas en alguno de los registros específicos existentes en las comunidades autónomas o ayuntamientos del lugar de residencia o formalizadas mediante documento público en el que conste la constitución de dicha unión de vida".

Y como ya he indicado con anterioridad, su tesis se basará en contrarrestar el parecer mayoritario con la aportación de datos estadísticos que demostrarían la existencia de la discriminación, acudiendo (véase con detalle el apartado 6) a censos de población, a documentos de la Comisión Europea y a estudios llevados a cabo por la Fundación Secretariado Gitano. Muy cuidadoso en la búsqueda de datos que pongan de manifiesto la discriminación indirecta sufrida por la población gitana, y en este caso concreto la recurrente de la pensión de viudedad, repasa los existentes sobre la situación de estado civil de la población romaní enfatizando que un estudio del Ministerio de Sanidad, Política Social e Igualdad del año 2011 ya ponía de manifiesto que "la unión de vida por su rito cultural tradicional de forma exclusiva" estaba presente en un $28 \%$ de las personas casadas de dicha comunidad, rechazando la tesis de la mayoría, calificada de "positivismo formalista estricto" de la neutralidad de la norma e interpretación administrativa y judicial efectuada, sino concluyendo que la tesis contraria, la existencia de la discriminación indirecta, "se impone de manera concluyente",

Conclusión palmaria de todo lo anteriormente expuesto a juicio del bien argumentado voto particular es que "sí existen efectos desfavorables para los 
miembros del pueblo romaní respecto de otros colectivos que opten por la no formalización de su unión de vida -bien sea a través de uniones matrimoniales registradas o uniones de vida inscritas en registros públicos- en cuanto al cumplimiento de este requisito para la obtención de la pensión de viudedad".

Por fin, la inexistencia de neutralidad de la norma debe llevar a continuación, siguiendo la jurisprudencia del TJUE y del propio TC, a analizar si la diferencia (desfavorable) de trato está debidamente justificada y es ajena a toda posible discriminación. Se apoya, completamente, en el ya analizado con anterioridad voto particular a la sentencia del TS y concluye que la formalidad requerida de la inscripción como pareja de hecho en un registro público para acreditar su existencia a efectos legales, queda satisfecha por "la realidad cultural de la comunidad romaní respecto de este tipo de uniones", de tal manera que su mantenimiento en este caso se convierte en un requisito desproporcionado "desde la perspectiva de la prohibición de discriminación".

\section{Parte dispositiva}

De acuerdo a toda la argumentación anteriormente expuesta, defendida por la mayoría de la Sala, el TC desestima la demanda de amparo promovida por doña Joaquina Cortés Cortés.

\section{Comentario}

Ni la sentencia del TCD ni ninguna otra de las restantes referenciadas aborda la discriminación múltiple o interseccional raza/género que hubiera llevado, de ser apreciada, a resoluciones judiciales que hubieran seguido siendo estimatorias del recurso, pero con una argumentación y fundamentación distintas en el caso del TEDH, y a la estimación del RCUD por el TS y del recurso de amparo por el TC.

No es este breve artículo el más apropiado para realizar un análisis detallado de esa discriminación que aúna raza/etnia y género por afectar a la misma persona, tanto en el caso de la sentencia del TEDH, coloquialmente conocida por el caso de "la Nena", como en el ahora resuelto por la STC 1/20001 de 25 de enero, sino solo el de apuntar algunos elementos críticos.

En dicha sentencia (STC 69/2007 de 23 de mayo) las alegaciones de la recurrente se basaron en la vulneración de sus derechos a la igualdad ante la ley "y a no ser discriminado por motivos de raza y condición social", sin plantearse esa posible discriminación también por razón de sexo y sin que, por supuesto, tampoco manifestaran nada al respecto en este punto tanto la parte recurrida, el INSS, como el MF. Tampoco el TC formuló valoración alguna al respecto, siendo el eje central de su argumentación, de acuerdo con la normativa vigente en aquel momento, que no existía vulneración alguna del art. 14 CE por la limitación del derecho a la pensión de viudedad a supuestos en los que concurriera un previo vínculo matrimonial. Reiteró el TC su tesis negativa de que pudiera existir una "discriminación por indiferenciación" al no consagrar el principio constitucional de igualdad "un derecho a la desigualdad de trato", y que tampoco ampara "la falta de distinción entre supuestos desiguales". La sentencia contó con el voto particular discrepante del magistrado Jorge RodríguezZapata, que defendió que hubiera debido otorgarse el amparo por haberse vulnerado el derecho de la recurrente en su condición de miembro de una "minoría desfavorecida", si bien tampoco entró en un análisis de la posible discriminación múltiple o interseccional.

EI TEDH estimó el recurso y se centró en la importancia de la buena fe de la parte recurrente al considerar, a partir de actuaciones de los poderes públicos nacionales, que su matrimonio por el rito gitano tenía validez legal. En su valoración de la sentencia, y aún reconociendo que el fallo le "encanta" pero mucho menos la argumentación ("limitado, poco coherente, escasamente riguroso y menos creativo aún"), el profesor Fernando Rey sostuvo que al no haber argumentado el TEDH "por la vía de las categorías del derecho antidiscriminatorio, en este caso, de la discriminación por indiferenciación (ni tampoco por la de discriminación indirecta o la 
de múltiple, que acaso podrían ser aplicables" ..... limitaba en el futuro su valor como precedente ("ya que será difícil encontrar supuestos comparables a los que sufrió la demandante"). Con anterioridad, y al analizar muy críticamente la sentencia del TC, el profesor Rey se refirió con toda claridad a que, a su parecer, se daba un supuesto de discriminación múltiple por razón de raza/etnia y de género ya que "a la recurrente se le impidió social y culturalmente trabajar fuera de casa (por ser mujer y gitana), se le impuso culturalmente contraer matrimonio de acuerdo con los usos gitanos (por ser mujer y gitana) y cuidar del marido hasta la muerte de éste (por ser mujer y gitana), pero se le negó jurídicamente una pensión de viudedad (por una circunstancia que en ningún caso hubiera sido jurídicamente aplicable a una mujer paya o fácticamente aplicable a un varón gitano) -es evidente que su experiencia de discriminación no la hubiera podido haber sufrido ni una mujer paya ni tampoco un varón gitano- es específica -es una discriminación múltiple- discriminación que no ha sido judicialmente reparada"[6], y de ahí que si se hubieran tomado en consideración esos factores mencionados, "posiblemente el Tribunal hubiera alcanzado otro fallo", ya que a su parecer se estaba "en presencia de un ejemplo prístino de discriminación múltiple y de género".

En idéntico sentido se manifestó la profesora Ruth Abril, para quien, además de la existencia de una discriminación étnica, hubiera podido argumentarse una discriminación por razón de sexo, por encontrarnos en el caso de una mujer que "como en la mayor parte de las familias, especialmente de esa época y especialmente entre las gitanas, se dedicaban al cuidado de la familia (seis hijos) y del hogar, dependiendo del sueldo del marido y en caso de la muerte del mismo, de su pensión de viudedad" [7]

¿Hubiera podido utilizarse el concepto de discriminación múltiple en esta sentencia del TEDH y también en las más recientes del TS y del TC? Sí, era factible a partir de las posibilidades ofrecidas por el art. 14 del Convenio Europeo de Derechos Humanos, y esta fue la tesis defendida con acierto, a mi parecer, por el magistrado, Fernando Lousada, que calificó la sentencia del TEDH de "oportunidad perdida", en el bien entendido que ya los tribunales españoles que conocieron del asunto habían concluido que "ni se la había discriminado (a la recurrente) por razón de sexo ni por razón de raza, pero analizando por separado ambas causas de discriminación".

Y ¿podría utilizarlo el TJUE? A partir de la redacción del art. 8 del Tratado de funcionamiento de la Unión Europea que establece el principio de transversalidad de la igualdad de trato y de oportunidades entre mujeres y hombres, Fernando Lousada concluye, también de forma acertada, a mi parecer, que "una discriminación interseccional debe ser judicialmente tutelada sin necesidad de ninguna intervención legislativa en orden a reconocer protección al colectivo de mujeres multidiscriminado", por cuanto una solución en sentido contrario "sería admitir que las directivas sobre raza y otras discriminaciones se pueden aplicar sin tomar en consideración el objetivo de conseguir la igualdad de sexos"[8].

\section{Referencias:}

1. ^ Fue objeto de mi examen en "Pensión de viudedad. Dos días, dos Salas, dos sentencias. Matrimonio por el rito gitano: no. Poligamia: si para la segunda (y restantes si las hubiere) esposa. Notas a las sentencias del TS (C-A y Social) de 24 y 25 de enero de 2018". http:// www.eduardorojotorrecilla.es/2018/02/pension-de-viudedad-dos-dias-dossalas.html (consulta: 19 de abril)

2. ^Es de muy recomendable lectura el artículo de la profesora María Emilia Casas "Igualdad y prohibición de discriminación por origen racial o étnico", 
y sobre la segunda el de la profesora María Fernanda Fernández "Igualdad y prohibición de discriminación en el marco laboral", ambos publicados en la obra colectiva "Derecho Social de la Unión Europea. Aplicación por el Tribunal de Justicia" (Ed. Francis Lefevre), dirigido por la profesora María Emilia Casas y el profesor Román Gil, págs.. 311-359.

3. ^ He abordado la temática en "Sobre la discriminación, directa e indirecta, por razón del origen racial o étnico. Nota a la sentencia del TJUE de 16 de julio(asunto C-83/14)" http://www.eduardorojotorrecilla.es/2015/08/sobre-ladiscriminacion-directa-e.html (consulta: 19 de abril), en la que me manifesté en estos términos: "para el TJUE el concepto de "discriminación basada en el origen étnico», debe interpretarse en el sentido de que, "en circunstancias como las del asunto principal, en las que todos los contadores eléctricos en un barrio habitado principalmente por personas de origen gitano están instalados en postes del tendido eléctrico aéreo a una altura de seis a siete metros, mientras que en los otros barrios los contadores están situados a una altura menor de dos metros, dicho concepto es aplicable con independencia de que esa medida colectiva afecte a las personas que tienen un origen étnico específico o a las que, sin tener ese origen, sufren junto con las primeras el trato menos favorable o la desventaja particular derivada de esa medida". Sobre la discriminación indirecta, nuevamente con apoyo en su propia doctrina, destaca que "puede producirse esa discriminación cuando la aplicación de una medida nacional, aunque formulada de manera neutra, desfavorece de hecho a un número mucho mayor de sujetos con la característica personal protegida que el de personas que carecen de ella"

4. ^ "Discriminación múltiple por razón de género y pertenencia a minoría étnica". Aequalitas Revista jurídica de igualdad de oportunidades entre mujeres y hombres. Núm. 26, 2010, págs. 6-15.

5. ^ https://Www.congreso.es/public_oficiales/L14/CONG/DS/CO/DSCD-14CO-247.PDF (consulta: 19 de abril).

6. ^ "La discriminación múltiple, una realidad antigua, un concepto nuevo", Revista Española de Derecho Constitucional, número 84, 2008, págs. 251-283.

7. ^ "El reconocimiento judicial de la discriminación múltiple en el ámbito europeo" Revista de Derecho Comunitario Europeo, núm. 44, enero-abril 2013, págs. 309-326.

8. ^ Encuentros y desencuentros entre el TEDH y el TJUE en materia de igualdad de género" Fémeris, Vol. 4, núm. 2, pags. 39-49 